\title{
BMJ Open Self-reported hearing loss in Russians: the population-based Ural Eye and Medical Study
}

\author{
Mukharram M Bikbov, ${ }^{1}$ Rinat R Fayzrakhmanov, ${ }^{1}$ Gyulli M Kazakbaeva, ${ }^{1}$ \\ Rinat M Zainullin, ${ }^{1}$ Venera F Salavatova, ${ }^{1}$ Timur R Gilmanshin, ${ }^{1}$ \\ Inga I Arslangareeva, ${ }^{1}$ Nikolai A Nikitin, ${ }^{1}$ Songhomitra Panda-Jonas, ${ }^{2}$ \\ Svetlana R Mukhamadieva, ${ }^{1}$ Dilya F Yakupova, ${ }^{1}$ Renat I Khikmatullin, ${ }^{1}$ \\ Said K Aminev, ${ }^{1}$ Ildar F Nuriev, ${ }^{1}$ Artur F Zaynetdinov, ${ }^{1}$ Yulia V Uzianbaeva, ${ }^{1}$ \\ Jost B Jonas ${ }^{\odot 3}$
}

To cite: Bikbov MM,

Fayzrakhmanov RR, Kazakbaeva GM, et al. Selfreported hearing loss in Russians: the populationbased Ural Eye and Medical Study. BMJ Open 2019;9:e024644. doi:10.1136/ bmjopen-2018-024644

- Prepublication history and additional material for this paper are available online. To view these files, please visit the journal online (http://dx.doi. org/10.1136/bmjopen-2018024644).

Received 11 June 2018 Revised 4 October 2018 Accepted 10 January 2019

Check for updates

(c) Author(s) (or their employer(s)) 2019. Re-use permitted under CC BY-NC. No commercial re-use. See rights and permissions. Published by BMJ.

${ }^{1}$ Ufa Eye Research Institute, Ufa, Russian Federation

${ }^{2}$ Augenpraxis Jonas,

Seegartenklinik, Heidelberg, Germany

${ }^{3}$ Department of Ophthalmology, Medical Faculty Mannheim, Ruprecht-Karls-University Heidelberg, Heidelberg, Germany

Correspondence to Professor Jost B Jonas; Jost.Jonas@medma.uniheidelberg.de

\section{ABSTRACT}

Objective With data on frequency of hearing loss in Russia and Eastern Europe generally lacking, we assessed the prevalence of hearing loss in a Russian population. Setting The population-based Ural Eye and Medical Study was conducted in the rural and urban regions of Bashkortostan, Russia.

Participants With an inclusion criterion of age $40+$ years, the study included 5899 (80.5\%) out of 7328 eligible individuals (mean age: $59.0 \pm 10.7$ years; range: $40-94$ years).

Primary and secondary outcome measures Hearing loss was examined in 5397 (91.5\%) study participants, assessed using a standardised interview with questions from the 'Hearing Handicap Inventory for the Elderly Screening Version (HHIE-S)'.

Results The prevalence of self-reported hearing loss (26.1\%, $95 \% \mathrm{Cl} 24.2$ to 27.2$)$ increased from $10.9 \%$ (95\% $\mathrm{Cl} 8.0$ to 13.7 ) in participants aged $40-45$ years old to $59.0 \%(95 \%$ Cl 51.6 to 66.4$)$ in those aged $80+$ years old. It was higher for men than for women in the $60-80$ years age group (38.93\%, $95 \%$ Cl 35.8 to 42.1 , vs $32.8 \%, 95 \%$ $\mathrm{Cl} 30.2$ to 35.3; $\mathrm{p}=0.003)$. On multivariable analysis, higher prevalence of hearing loss was associated with older age $(p<0.001 ; 0 R$ [per year of age]: 1.06 [1.06 to 1.07]), male gender ( $p<0.001 ; 0 R: 1.26$ [1.09 to 1.47$])$, higher depression score $(p<0.001 ; 0 R: 1.06$ [1.04 to $1.08])$, higher prevalence of headache $(p=0.001 ; 0 R$ : 1.27 [1.10 to 1.47]), history of cardiovascular diseases including stroke ( $\mathrm{p}=0.001 ; \mathrm{OR}: 1.32$ [1.13 to 1.55$]$ ), and osteoarthritis ( $p<0.001 ;$ OR: 1.40 [1.18 to 1.67$])$, physically vigorous activity during work $(p<0.001 ; 0 R: 1.40[1.21$ to 1.62]), alcohol consumption ( $\mathrm{p}<0.001 ; \mathrm{OR}: 1.51$ [1.28 to 1.78]), and dry eye feeling ( $\mathrm{p}<0.001 ; \mathrm{OR}: 1.67$ [1.30 to 2.16]). It was marginally correlated with a higher anxiety score ( $p=0.07 ; 0 R: 1.03$ [0.998 to 1.06$])$. It was independent of diabetes $(p=0.52)$, arterial hypertension $(p=0.20)$, level of education $(p=0.11)$, region of habitation $(p=0.70)$, blood concentration of high-density lipoproteins $(p=0.17)$ and low-density lipoproteins $(p=0.52)$, current smoking $(\mathrm{p}=0.95)$ and smoking pack-years $(\mathrm{p}=0.37)$, and best corrected visual acuity $(p=0.93)$.

Conclusions As in other countries the prevalence of hearing loss is high in this elderly population in Russia.

\section{Strengths and limitations of this study}

- The assessment of hearing loss in an interview containing a series of 11 standardised questions without performing an audiometric examination was a limitation of the study.

- Although noise is a major determinant of hearing loss along with ageing, exposure to noise at the workplace was not directly and specifically assessed in the study.

- Performing the study in Russia, where no population-based data on hearing loss have been available so far, was a strength of the investigation.

- The study sample size of 5899 participants and the participation rate of $80.5 \%$ were strengths of the study.

- The relatively high number of parameters examined in addition to hearing loss and enabling a wide search for associations between hearing loss and other parameters were strengths of the investigation.

It is primarily or secondarily associated with older age, depression, male gender, cardiovascular disease and alcohol consumption.

\section{INTRODUCTION}

Deficits in the function of sensory organs are a major cause of the so-called disability-associated life years (DALYs). ${ }^{1}$ In the Global Burden of Disease Study 2016, sense organ diseases caused 66.7 million DALYS (95\% uncertainty interval [UI]: 46.5-92.3 million) or $2.8 \%$ of all DALYs in 2016, up from 39.4 million DALYS (95\% UI: $27.3-54.5$ million) in 1995 and 54.8 million DALYs (95\% CI 38.276.0 million) in 2006. ${ }^{1}$ Sense organ diseases-associated DALYs increased in the ranking of the most common causes of DALYs, from rank 16 in 1995 to rank 14 in 2006, and to rank 7 in 2016. ${ }^{1}$ Age-related and other 
hearing loss accounted for 29.7 million DALYS (95\% UI: 25.3-50.9 million) or $44.5 \%$ of all sense organs-associated DALYs in $2016{ }^{1}$

Despite its importance for public health, the prevalence of hearing loss and its associated factors has not been widely investigated worldwide. ${ }^{2-11}$ For many countries, data on the prevalence of hearing loss are not yet available, and the factors associated with hearing loss have not been examined in a detailed manner. This holds true in particular for Russia and Eastern Europe. We therefore conducted this study to assess the prevalence of hearing loss in a Russian population and to explore the associations of hearing loss with other parameters such as gender, region of habitation and level of education.

\section{METHODS}

The Ural Eye and Medical Study (UEMS) is a population-based investigation performed in the Russian Republic of Bashkortostan, in its capital Ufa (Kirovskii region) and in a rural region consisting of villages in the Karmaskalinsky District. The latter was located at a distance of $65 \mathrm{~km}$ from Ufa. ${ }^{12-14}$ The inclusion criteria were living in the study regions and age $40+$ years. Assuming a participation rate of approximately $80 \%$ and aiming at a study population size of about 5500-6000 participants, the number of eligible individuals was calculated to be approximately $7000-7500$. The number of study participants (ie, 55006000 ) was based on experience gained from previous population-based investigations, the study populations of which were assumed to have similar prevalence of major diseases as the present study population.

The first part of the series of examinations was a standardised interview. It was conducted by trained social workers and consisted of more than 250 standardised questions on parameters of various fields such as socioeconomics, diet, alcohol and tobacco consumption, physical exercise, and medical history. ${ }^{12} 1315$ The Guidelines for Accurate and Transparent Health Estimates Reporting were applied in reporting the data. ${ }^{16}$

As recently described in detail, the series of examination further consisted of measurements of arterial blood pressure, pulse rate and body height and weight, handgrip strength (as measured by dynamometry), blood concentrations of glucose, blood lipids and other substances, and pulmonary function (spirometry). ${ }^{12} 13$ Arterial hypertension was defined by a systolic blood pressure $\geq 140 \mathrm{~mm}$ $\mathrm{Hg}$ and/or diastolic blood pressure $\geq 90 \mathrm{~mm} \mathrm{Hg}$, and/ or self-reported history or current treatment of arterial hypertension with antihypertensive medication. Diabetes mellitus was defined by a blood glucose concentration $\geq 7.0 \mathrm{mmol} / \mathrm{L}$, or a self-reported history of physician diagnosis or of therapy for diabetes mellitus.

Hearing loss was assessed by a series of 11 standardised questions, 10 of which were derived from the 'Hearing Handicap Inventory for the Elderly Screening Version (HHIE-S)' (box 1). ${ }^{17-19}$ The questions could be answered by 'no' ( 0 point), 'sometimes' ( 2 points) and 'yes' (4
Box 1 Standardised questions to assess the presence and sequels of hearing problems

Do you experience a hearing loss?

Does a hearing problem make you feel embarrassed when meeting new people?

- Does a hearing problem make you feel frustrated when talking to members of your family?

- Do you have difficulties hearing when someone speaks in a whisper?

- Do you feel handicapped by a hearing problem?

- Does a hearing problem cause you difficulties when visiting friends, relatives or neighbours?

- Does a hearing problem make you attending religious services less often than you would like?

- Does a hearing problem make you having arguments with family members?

- Does a hearing problem cause you difficulties when listening to television or radio?

- Do you feel that any difficulty with your hearing limits or does it hamper your personal or social life?

- Does a hearing problem cause you difficulty when you are in a restaurant together with relatives or friends?

points). The total hearing loss score was the sum of all points and could range between 0 and 44 points. The amount of hearing loss was assessed by the hearing loss score. The HHIE-S had been applied in previous investigations. ${ }^{17-19}$ The diagnostic performance of the HHIE-S against five definitions of hearing loss as assessed by puretone audiometry had been investigated in a previous study on 178 elderly subjects. ${ }^{20}$ The HHIE-S had sensitivities ranging from $53 \%$ to $72 \%$ and specificities ranging from $70 \%$ to $84 \%$ in the different definitions. The receiver operating characteristics and the likelihood ratios of the HHIE-S were similar regardless of the hearing loss definitions. Another investigation had examined the reliability, validity and associations of the HHIE-S with quality of life measures, such as subjective well-being, depressive symptoms, subjective loneliness and physical functioning. ${ }^{21}$ The investigation revealed that the reliability of the HHIE-S was relatively high, with a Cronbach's alpha coefficient of 0.91, a Spearman-Brown coefficient of 0.90 and an intraclass correlation coefficient of 0.85 . The prevalence of self-reported hearing loss as a binary variable was assessed using a single question: 'Do you experience a hearing loss?' We additionally carried out Weber's test and Rinne's test.

Using a statistical software program (Statistical Package for Social Science, SPSS V.25.0), we first calculated the prevalence of hearing loss and then assessed its associations with other parameters on univariate analysis. Finally, we performed a multivariable regression analysis with the hearing loss score as the dependent variable. The list of independent variables included all those variables which were associated $(p \leq 0.10)$ with the hearing loss score on univariate analysis. Multicollinearity was also tested. The prevalence of hearing loss was analysed in a binary regression analysis. We assessed the ORs and their 
$95 \%$ CIs, and the level of statistical significance was set as $\mathrm{p}<0.05$.

\section{Patient and public involvement}

Patients were not involved in the study.

\section{RESULTS}

Out of a total population of 7328 eligible individuals, 5899 $(80.5 \%)$ participated in the UEMS. Out of these, data on hearing loss score were available for 5397 (91.5\%) individuals (2450 men, $45.4 \%$ ). Their mean age was $58.6 \pm 10.6$ years (range: $40-94$ years). The study population did not differ markedly in age and sex composition from the Russian population as published in the 2010 census. ${ }^{22}$

Subjects with data on hearing loss as compared with individuals without hearing loss data had a significantly younger age $(p<0.001)$ and were significantly more often men $(p<0.001)$. The mean hearing loss score was $5.13 \pm 10.95$ (median: 0 ; range: $0-44$ ). Within the group of ethnic Russians ( $\mathrm{n}=1185$; age: $60.1 \pm 11.1$ years), the mean hearing loss score was 5.58 \pm 11.09 (median: 0; range: $0-44)$, with no significant $(\mathrm{p}=0.11)$ difference from the non-Russian group. An abnormal result of Weber's test was found in 210 (3.9\%, 95\% CI 3.4 to 4.4$)$ study participants and an abnormal result for Rinne's test in 3390 (63.0\%, 95\% CI 61.7 to 64.3$)$ individuals. The hearing loss score differed significantly between individuals with a positive Weber's test and those with a negative Weber's test $(23.9 \pm 14.7$ vs $4.4 \pm 10.1 ; \mathrm{p}<0.001)$.

On univariate analysis, a higher hearing loss score was correlated with parameters such as older age $(\mathrm{p}<0.001)$ (table 1, figure 1), male gender $(\mathrm{p}<0.001)$ (figure 1) and other variables (online supplementary table 1 ). The multivariable regression analysis included the hearing loss score as the dependent variable, and as independent variables all those parameters which were associated $(p \leq 0.10)$ with the hearing loss score on univariate analysis. Due to collinearity, we first dropped the parameters body weight (variance inflation factor [VIF]: 6.8) and waist circumference (VIF: 4.0). We then dropped step by step parameters such as prevalence of arterial hypertension which were no longer statistically significantly associated with hearing loss on multivariate analysis. In the resulting final model, a higher hearing loss score was associated (regression coefficient $r$ : 0.33$)$ with older age $(p<0.001)$, male gender $(p<0.001)$, higher depression score $(p<0.001)$, higher prevalence of headache $(\mathrm{p}<0.001)$, history of cancer $(\mathrm{p}=0.008)$, cardiovascular diseases including stroke $(\mathrm{p}=0.003)$, and osteoarthritis $(\mathrm{p}=0.006)$ and skin disease $(p=0.01)$, lower number of days with intake of fruits $(p=0.02)$, and higher amount of physically vigorous activity during work $(\mathrm{p}=0.008)$ and of physically moderate activity during leisure time $(\mathrm{p}<0.001)$ (table 2$)$.

Hearing loss defined as a binary variable (question: 'Do you experience a hearing loss?') was prevalent in 1406 (26.1\%, 95\% CI 24.2 to 27.2) participants. It was significantly associated with a positive Weber's test (OR:
Table 1 Mean hearing loss score in the Ural Eye and Medical Study, stratified by sex and age

\begin{tabular}{|c|c|c|c|}
\hline $\begin{array}{l}\text { Age group } \\
\text { (years) }\end{array}$ & $\mathbf{n}$ & $\begin{array}{l}\text { Hearing loss } \\
\text { score }\end{array}$ & $95 \% \mathrm{Cl}$ \\
\hline \multicolumn{4}{|l|}{ Men } \\
\hline 40-44 & 209 & $2.1 \pm 7.4$ & 1.0 to 3.1 \\
\hline $45-49$ & 350 & $1.9 \pm 6.9$ & 1.2 to 2.7 \\
\hline $50-54$ & 422 & $2.9 \pm 8.4$ & 2.1 to 3.7 \\
\hline $55-59$ & 471 & $4.7 \pm 10.6$ & 3.7 to 5.6 \\
\hline $60-64$ & 383 & $7.6 \pm 13.2$ & 6.3 to 8.9 \\
\hline $65-69$ & 273 & $8.5 \pm 13.4$ & 6.9 to 10.1 \\
\hline $70-74$ & 124 & $8.5 \pm 13.1$ & 6.1 to 10.8 \\
\hline $75-79$ & 150 & $10.9 \pm 14.7$ & 8.5 to 13.3 \\
\hline $80+$ & 68 & $15.9 \pm 16.2$ & 12.0 to 19.8 \\
\hline \multicolumn{4}{|l|}{ Women } \\
\hline $40-44$ & 252 & $1.2 \pm 4.4$ & 0.7 to 1.8 \\
\hline $45-49$ & 361 & $2.2 \pm 7.1$ & 1.4 to 2.9 \\
\hline $50-54$ & 465 & $3.1 \pm 8.7$ & 2.3 to 3.9 \\
\hline $55-59$ & 500 & $4.1 \pm 9.6$ & 3.3 to 5.0 \\
\hline $60-64$ & 449 & $4.8 \pm 10.0$ & 3.9 to 5.7 \\
\hline $65-69$ & 430 & $5.8 \pm 11.3$ & 4.7 to 6.8 \\
\hline $70-74$ & 182 & $6.2 \pm 10.9$ & 4.6 to 7.8 \\
\hline $75-79$ & 203 & $10.8 \pm 14.8$ & 8.7 to 12.8 \\
\hline $80+$ & 105 & $15.3 \pm 15.6$ & 12.2 to 18.3 \\
\hline
\end{tabular}

24.0, 95\% CI 15.7 to 36.7). The prevalence of hearing loss increased with older age ( $\mathrm{p}<0.001$; OR: $1.06,95 \%$ CI 1.05 to 1.07 ) (table 3 ). In the age group between 60 and $<80$ years, the prevalence of hearing loss was significantly $(\mathrm{p}=0.003)$ higher in men than in women $(38.93 \%$, $95 \%$ CI 35.8 to 42.1 , vs $32.8 \%, 95 \%$ CI 30.2 to 35.3 ). For the age group older than 60 years $(\mathrm{p}=0.57)$ and for the age group $80+$ years $(p=0.87)$, both genders did not differ

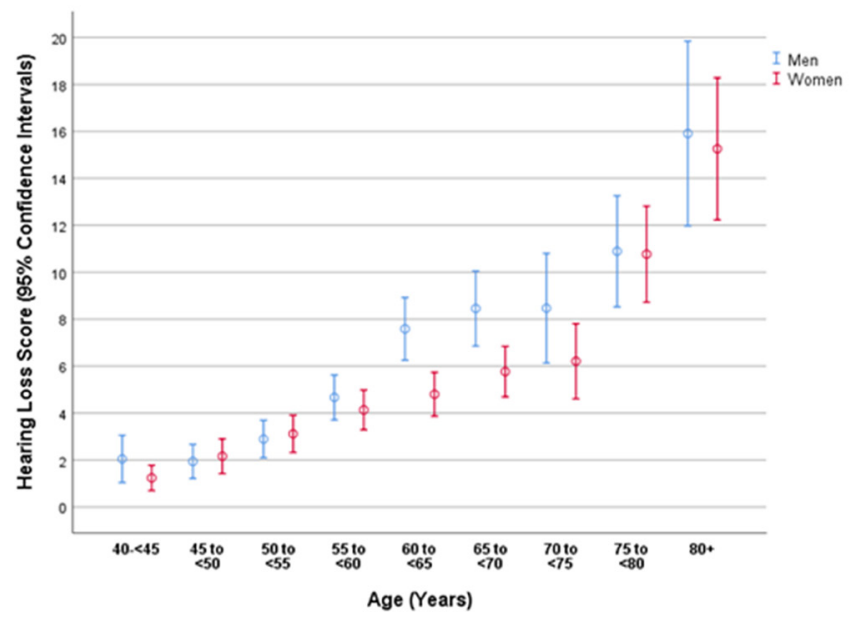

Figure 1 Graph showing the distribution of the hearing loss score stratified by age and gender in the Ural Eye and Medical Study. 
Table 2 Associations (multivariate analysis) between the hearing loss score and other systemic parameters in the Ural Eye and Medical Study

\begin{tabular}{|c|c|c|c|c|c|}
\hline Parameters & $P$ value & $\begin{array}{l}\text { Standardised } \\
\text { regression } \\
\text { coefficient beta }\end{array}$ & $\begin{array}{l}\text { Non-standardised } \\
\text { regression } \\
\text { coefficient B }\end{array}$ & $95 \% \mathrm{Cl}$ & $\begin{array}{l}\text { Variance } \\
\text { inflation factor }\end{array}$ \\
\hline Age (years) & $<0.001$ & 0.23 & 0.27 & 0.23 to 0.31 & 1.14 \\
\hline Sex (women/men) & $<0.001$ & 0.07 & 1.69 & 0.89 to 2.50 & 1.13 \\
\hline Depression score & $<0.001$ & 0.07 & 0.22 & 0.11 to 0.33 & 1.11 \\
\hline History of headache & $<0.001$ & 0.07 & 1.50 & 0.71 to 2.29 & 1.09 \\
\hline History of cancer & 0.008 & 0.05 & 3.53 & 0.91 to 6.16 & 1.01 \\
\hline $\begin{array}{l}\text { History of cardiovascular diseases } \\
\text { including stroke }\end{array}$ & 0.003 & 0.05 & 1.45 & 0.51 to 2.39 & 1.11 \\
\hline History of osteoarthritis & 0.006 & 0.05 & 1.43 & 0.42 to 2.44 & 1.06 \\
\hline History of skin disease & 0.01 & 0.04 & 2.18 & 0.48 to 3.89 & 1.01 \\
\hline $\begin{array}{l}\text { In a week how many days do you eat } \\
\text { fruits? }\end{array}$ & 0.02 & -0.04 & -0.24 & -0.44 to 0.04 & 1.03 \\
\hline $\begin{array}{l}\text { 'Does your work involve physically } \\
\text { vigorous activity (like heavy lifting or } \\
\text { digging) or moderately intensive activity } \\
\text { (like brisk walking or carrying light } \\
\text { loads) during work for at least } 10 \text { min at } \\
\text { a time?' }\end{array}$ & 0.042 & 0.04 & 1.13 & 0.04 to 2.22 & 1.04 \\
\hline $\begin{array}{l}\text { 'How many days a week do you do } \\
\text { such physically vigorous activity during } \\
\text { work?' }\end{array}$ & 0.008 & 0.05 & 0.36 & 0.10 to 0.63 & 1.10 \\
\hline $\begin{array}{l}\text { 'In your leisure time, do you do any } \\
\text { moderate intensity activities like brisk } \\
\text { walking, cycling or swimming for at } \\
\text { least } 10 \text { min at a time?' }\end{array}$ & $<0.001$ & 0.09 & 1.96 & 1.19 to 2.74 & 1.03 \\
\hline
\end{tabular}

significantly in the prevalence of hearing loss (figure 2). In the total study population, the prevalence of hearing loss increased from $10.9 \%$ (95\% CI 8.0 to 13.7 ) in the age group 40 to $<45$ years, to $22.7 \%$ (95\% CI 20.0 to 25.4 ) in the age group 55 to $<60$ years, and to $59.0 \%$ (95\% CI 51.6 to 66.4 ) in the age group $80+$ years (figure 2 ).

On multivariable binary regression analysis, higher prevalence of hearing loss was associated with older age $(p<0.001)$, male gender $(p<0.001)$, higher depression score $(\mathrm{p}<0.001)$, higher prevalence of headache $(\mathrm{p}=0.001)$, history of cancer $(\mathrm{p}=0.04)$, cardiovascular diseases including stroke $(\mathrm{p}=0.001)$, and osteoarthritis $(\mathrm{p}<0.001)$, higher amount of physically vigorous activity during work $(\mathrm{p}<0.001)$, and higher prevalence of alcohol consumption $(p<0.001)$ and of dry eye feeling $(p<0.001)$ (table 4). Prevalence of hearing loss was marginally correlated with a higher anxiety score, when added to the model ( $p=0.07$; OR: $1.03,95 \%$ CI 0.998 to 1.06 ). If diabetes $(p=0.52)$, arterial hypertension $(p=0.20)$, level of education ( $\mathrm{p}=0.11$; OR: $0.97,95 \%$ CI 0.93 to 1.01 ), urban versus rural region of habitation $(\mathrm{p}=0.70)$, blood concentration of high-density lipoproteins $(\mathrm{p}=0.17)$ and low-density lipoproteins $(\mathrm{p}=0.52)$, current smoking $(\mathrm{p}=0.95)$ and smoking pack-years $(\mathrm{p}=0.37)$, best corrected visual acuity $(\mathrm{p}=0.93)$ and presenting visual acuity $(\mathrm{p}=0.62)$, and anxiety score ( $\mathrm{p}=0.07$; OR: $1.03,95 \%$ CI 0.998 to 1.06 ) were added to the model, these variables were not significantly associated with hearing loss.

\section{DISCUSSION}

In this Russian population, the prevalence of hearing loss increased from $10.9 \%$ in participants aged $40-45$ years old to $59.0 \%$ in those aged $80+$ yearsold. It was associated with older age, male gender, higher depression score, higher prevalence of headache, history of cardiovascular diseases including stroke, and osteoarthritis, physically vigorous activity during work, alcohol consumption, and dry eye feeling. It was marginally significantly correlated with higher anxiety score $(\mathrm{p}=0.07)$.

The findings obtained in our study on a population in Russia can be compared with observations made in previous investigations conducted in other regions of the world. The high overall prevalence of hearing loss of $26.1 \%$ (95\% CI 24.2 to 27.2 ) in our study population aged $40+$ years agreed well with the data of the WHO that over $5 \%$ of the total world's population-or 466 million people-has disabling hearing loss (432 million adults and 34 million children) ${ }^{23}$ The prevalence of hearing loss as found in our study population also agreed well 
Table 3 Prevalence of self-reported hearing loss (definite answer of 'Yes' [in contrast to the answer of 'Sometimes' or 'No'] to the question 'Do you experience a hearing loss?') stratified by age and gender in the Ural Eye and Medical Study

\begin{tabular}{|c|c|c|c|}
\hline $\begin{array}{l}\text { Age group } \\
\text { (years) }\end{array}$ & $\mathbf{n}$ & $\begin{array}{l}\text { Prevalence of } \\
\text { self-reported } \\
\text { hearing loss }\end{array}$ & $95 \% \mathrm{Cl}$ \\
\hline \multicolumn{4}{|l|}{ Men } \\
\hline $40-44$ & 209 & 10.1 & 5.9 to 14.2 \\
\hline $45-49$ & 350 & 13.4 & 9.8 to 17.0 \\
\hline $50-54$ & 422 & 17.5 & 13.9 to 21.2 \\
\hline $55-59$ & 471 & 22.3 & 18.5 to 26.1 \\
\hline $60-64$ & 383 & 32.3 & 27.7 to 37.1 \\
\hline $65-69$ & 273 & 40.3 & 34.4 to 46.2 \\
\hline $70-74$ & 124 & 41.1 & 32.3 to 49.9 \\
\hline $75-79$ & 150 & 51.3 & 43.2 to 59.4 \\
\hline $80+$ & 68 & 60.3 & 48.4 to 72.2 \\
\hline \multicolumn{4}{|l|}{ Women } \\
\hline $40-44$ & 252 & 11.5 & 7.5 to 15.5 \\
\hline $45-49$ & 361 & 14.7 & 11.0 to 18.4 \\
\hline $50-54$ & 465 & 18.1 & 14.6 to 21.6 \\
\hline $55-59$ & 500 & 23.0 & 19.3 to 26.7 \\
\hline $60-64$ & 449 & 27.4 & 23.3 to 31.5 \\
\hline $65-69$ & 430 & 31.9 & 27.4 to 36.3 \\
\hline $70-74$ & 182 & 32.4 & 25.6 to 39.3 \\
\hline $75-79$ & 203 & 46.8 & 39.9 to 53.7 \\
\hline $80+$ & 105 & 58.1 & 48.5 to 67.7 \\
\hline
\end{tabular}

with figures found by Ikeda and colleagues ${ }^{24}$ for the USA, and with other data reported for the USA by the Health, Aging and Body Composition Study after adjusting for age differences in the study populations. ${ }^{25}$ The prevalence of hearing loss in our study population was lower than the figures found by Hannula and associates ${ }^{26}$ for Northern Finland (prevalence of self-reported hearing problems of $37.1 \%$ and of $43.3 \%$ for difficulties in following a conversation in noise), and it was lower than the prevalence of unilateral and bilateral speech-frequency hearing impairments in the National Health and Nutrition Examination Survey (NHANES) for the USA. ${ }^{27-29}$

In all the previous studies as in our investigation, the prevalence of hearing loss strongly increased with older age for both genders (figures 1 and 2). ${ }^{2730-46}$ In our study population, the age-related increase in the prevalence of hearing loss was less marked for women than for men in the age group 60 to $<80$ years (figures 1 and 2). As in the previous studies on other ethnicities, the frequency of hearing loss was higher for men than for women. ${ }^{27} 29-46$ In our study, the gender difference holds true for the age group 60 to $<80$ years $(38.93 \%$, 95\% CI 35.8 to 42.1 , vs $32.8 \%, 95 \%$ CI 30.2 to $35.3 ; \mathrm{p}=0.003)$. In the age group between 60 and $<80$ years, the prevalence of hearing

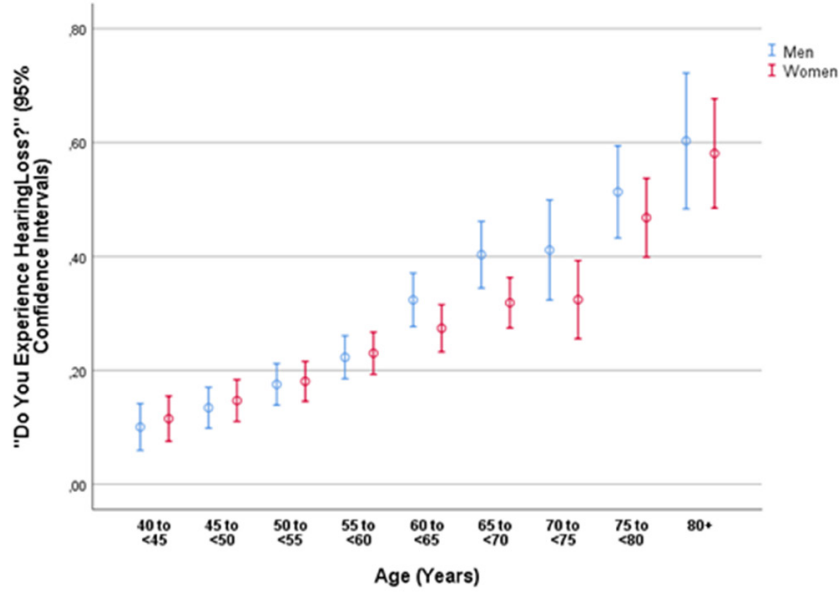

Figure 2 Graph showing the prevalence of self-reported hearing loss (defined by a definite answer of 'Yes' [in contrast to the answer of 'Sometimes' or 'No'] to the question 'Do you experience a hearing loss?') stratified by age and gender in the Ural Eye and Medical Study.

loss was significantly $(\mathrm{p}=0.003)$ higher for men than for women $(38.93 \%, 95 \%$ CI 35.8 to 42.1 , vs $32.8 \%, 95 \%$ CI 30.2 to 35.3$)$. For the age group younger than 60 years $(\mathrm{p}=0.57)$ and for the age group $80+$ years $(\mathrm{p}=0.87)$, both genders did not differ significantly in the prevalence of hearing loss.

In our study, a higher prevalence of hearing loss was associated with a higher prevalence of vigorous physical activity during work. It was in contrast to the finding reported by Gispen and coworkers, ${ }^{39}$ who used data from the National Health and Nutritional Examination Survey (2005-2006) and found that individuals with moderate or greater hearing impairment had greater odds than those with normal hearing of being in a lower category of physical activity. The association between vigorous physical activity at work and higher prevalence of hearing loss in our study might have been due to a potentially confounding correlation between heavy work and higher noise level at work.

In the NHANES and in a study by Sommer et $a l^{9}$ hearing impairment was more prevalent among adults with diabetes in a multivariable analysis. It is in contrast to our study where neither diabetes nor blood concentrations of glucose were significantly correlated with hearing loss (online supplementary table 1). As a corollary, the hearing loss in our study was not significantly correlated with body mass index (online supplementary table 1). It is in partial contrast to the results of the study by Lalwani and colleagues ${ }^{37}$ who found that in children 12-19 years of age, obese adolescents as compared with adolescents with normal body weight had elevated pure-tone hearing thresholds and greater prevalence of unilateral low-frequency sensorineural hearing loss $(\mathrm{p}=0.01)$.

A higher prevalence of self-reported hearing impairment was associated with a higher depression score in our study as well as in the study by $\mathrm{Li}$ and colleagues, ${ }^{38}$ who used data from the NHANES 2005-2010. They found 
Table 4 Associations (multivariate analysis) between the prevalence of hearing loss (definite answer of 'Yes' [in contrast to the answer of 'Sometimes' or 'No'] to the question 'Do you experience a hearing loss?') and other systemic parameters in the Ural Eye and Medical Study

\begin{tabular}{|c|c|c|c|}
\hline Parameters & $P$ value & OR & $95 \% \mathrm{Cl}$ \\
\hline Age (years) & $<0.001$ & 1.06 & 1.06 to 1.07 \\
\hline Sex (men/women) & $<0.001$ & 1.26 & 1.09 to 1.47 \\
\hline History of headache & 0.001 & 1.27 & 1.10 to 1.47 \\
\hline History of cancer & 0.04 & 1.51 & 1.02 to 2.24 \\
\hline History of osteoarthritis & $<0.001$ & 1.40 & 1.18 to 1.67 \\
\hline $\begin{array}{l}\text { 'Does your work involve physically vigorous activity (like heavy } \\
\text { lifting or digging) or moderately intensive activity (like brisk walking } \\
\text { or carrying light loads) during work for at least } 10 \text { min at a time?' }\end{array}$ & $<0.001$ & 1.40 & 1.21 to 1.62 \\
\hline Alcohol consumption & $<0.001$ & 1.51 & 1.28 to 1.78 \\
\hline
\end{tabular}

that self-reported hearing impairment and audiometrically determined hearing loss were significantly associated with depression, particularly in women.

The association between hearing loss and cardiovascular risk factors has remained unclear so far. While in our study population and in a study by Lohi et at ${ }^{41}$ cardiovascular risk factors were not significantly associated with hearing loss, the NHANES and the Health, Aging and Body Composition Study reported that cardiovascular risk generated by smoking and diabetes was associated with both high-frequency and low-frequency hearing loss. ${ }^{26} 293035$ Reasons for the discrepancy between the studies may have been differences in the study population (lifestyle in Russia vs lifestyle in the USA or in Korea), differences in the multivariable analysis and others.

The limitations of our study should be discussed. First, the main outcome parameter was self-reported hearing loss assessed using a series of 11 standardised questions. In previous studies, audiometry was used to quantify hearing impairment. Although the latter method is a more quantitative one, the degree of self-reported hearing impairment as compared with audiometrically defined hearing loss may be more important to reflect the quality of the daily life of the individual. Interestingly, a study by Hannula et $a t^{26}$ showed that self-reported hearing difficulties were more frequent than hearing impairment defined by audiometric measurement. Hannula et $a l^{26}$ also reported that self-reported hearing difficulties predicted hearing impairment at high frequencies $(4-8 \mathrm{kHz})$ rather than at frequencies of $0.5-4 \mathrm{kHz}$, which were commonly used to define the degree of hearing impairment in medical and legal issues. The test-retest reliability of the Hearing Handicap Inventory for Adults was evaluated in a study showing a correlation coefficient of $\mathrm{r}^{2}=0.940 .{ }^{46}$ In another investigation, the HHIE-S showed a significant reduction in perceived emotional and social/situational effects of hearing impairment following the use of hearing aids. ${ }^{47}$ Second, although noise is a major determinant of hearing loss along with ageing, exposure to noise at the workplace was not specifically assessed in the study. This lack of data on noise exposure was therefore one of the limitations of the study. The amount of physical activity at the workplace, however, was evaluated, and in the multivariable model a higher hearing loss score was associated with a higher amount of physically vigorous activity during work $(\mathrm{p}=0.008)$ (table 2). Although the amount of physical activity at the workplace is not a direct measure of noise exposure, both parameters are correlated with each other so that a higher amount of physically vigorous activity during work may be a surrogate for an increased noise exposure.

In conclusion, in our typically ethically mixed, urban and rural, Russian population aged $40+$ years, the mean prevalence of hearing loss was $26.1 \%$ and increased from $10.9 \%$ in those aged $40-45$ years old to $59.0 \%$ in those aged $80+$ years old. In addition to older age, the prevalence of hearing loss was associated with male gender, depression, higher prevalence of headache, history of cardiovascular diseases including stroke, physically vigorous activity during work, alcohol consumption and dry eye feeling, and marginally significantly correlated with higher anxiety score. These data may be useful to assess the epidemiology of hearing loss in Russia and to assess factors associated with hearing impairment in Russia.

Contributors Design and conception: MMB, RRF, GMK, JBJ. Data assessment: MMB, RRF, GMK, ZMR, IIA, TRG, VFS, NAN, SRM, DFY, RIK, AFZ, YVU, SKA, IFN, JBJ. Statistical analysis: JBJ, SP-J. Writing of the manuscript: JBJ, SP-J. Editing and final approval of the manuscript: MMB, RRF, GMK, ZMR, VFS, TRG, IIA, NAN, SP-J, SRM, DFY, RIK, SKA, IFN, AFZ, YVU, JBJ.

Funding The authors have not declared a specific grant for this research from any funding agency in the public, commercial or not-for-profit sectors.

Competing interests None declared.

Patient consent for publication Not required.

Ethics approval The Ethics Committee of the Academic Council of the Ufa Eye Research Institute approved the study, and informed written consent was obtained from all participants. 
Provenance and peer review Not commissioned; externally peer reviewed.

Data sharing statement There are no additional data to be shared.

Open access This is an open access article distributed in accordance with the Creative Commons Attribution Non Commercial (CC BY-NC 4.0) license, which permits others to distribute, remix, adapt, build upon this work non-commercially, and license their derivative works on different terms, provided the original work is properly cited, appropriate credit is given, any changes made indicated, and the use is non-commercial. See: http://creativecommons.org/licenses/by-nc/4.0/.

\section{REFERENCES}

1. GBD 2016 DALYs and HALE Collaborators. Global, regional, and national disability-adjusted life-years (DALYs) for 333 diseases and injuries and healthy life expectancy (HALE) for 195 countries and territories, 1990-2016: a systematic analysis for the Global Burden of Disease Study 2016. Lancet 2017;390:1260-344.

2. Cruickshanks KJ, Klein R, Klein BE, et al. Cigarette smoking and hearing loss: the epidemiology of hearing loss study. JAMA 1998;279:1715-9.

3. Vilayur E, Gopinath B, Harris DC, et al. The association between reduced GFR and hearing loss: a cross-sectional population-based study. Am J Kidney Dis 2010;56:661-9.

4. Béria JU, Raymann BC, Gigante LP, et al. Hearing impairment and socioeconomic factors: a population-based survey of an urban locality in southern Brazil. Rev Panam Salud Publica 2007;21:381-7.

5. Klein BE, Cruickshanks KJ, Nondahl DM, et al. Cataract and hearing loss in a population-based study: the Beaver Dam studies. Am J Ophthalmol 2001;132:537-43.

6. Raynor LA, Pankow JS, Miller MB, et al. Familial aggregation of agerelated hearing loss in an epidemiological study of older adults. Am J Audiol 2009;18:114-8.

7. Gurgel RK, Ward PD, Schwartz S, et al. Relationship of hearing loss and dementia: a prospective, population-based study. Otol Neurotol 2014;35:775-81.

8. Su P, Hsu CC, Lin HC, et al. Age-related hearing loss and dementia: a 10-year national population-based study. Eur Arch Otorhinolaryngol 2017;274:2327-34.

9. Sommer J, Brennan-Jones CG, Eikelboom RH, et al. A populationbased study of the association between dysglycaemia and hearing loss in middle age. Diabet Med 2017;34:683-90.

10. Asghari A, Farhadi M, Daneshi A, et al. The prevalence of hearing impairment by age and gender in a population-based study. Iran $J$ Public Health 2017:46:1237-46.

11. Smith AK, Ritchie CS, Miao Y, et al. Self-reported hearing in the last 2 years of life in older adults. J Am Geriatr Soc 2016;64:1486-91.

12. Bikbov M, Fayzrakhmanov RR, Kazakbaeva G, et al. Ural eye and medical study: description of study design and methodology. Ophthalmic Epidemiol 2018;25:187-98.

13. Bikbov MM, Fayzrakhmanov RR, Kazakbaeva GM, et al. Frequency and Associated Factors of Bone Fractures in Russians: The Ural Eye and Medical Study. Sci Rep 2018;8:7483.

14. Wikipedia. Bashkortostan. https://en.wikipedia.org/wiki/ Bashkortostan (Assessed 4 Mar 2018).

15. Folstein MF, Folstein SE, McHugh PR. "Mini-mental state". A practical method for grading the cognitive state of patients for the clinician. J Psychiatr Res 1975;12:189-98.

16. Stevens GA, Alkema L, Black RE, et al. Guidelines for accurate and transparent health estimates reporting: the GATHER statement. Lancet 2016;388:e19-23.

17. Aiello CP, Lima II, Ferrari DV. Validity and reliability of the hearing handicap inventory for adults. Braz J Otorhinolaryngol 2011;77:432-8.

18. Souza VC, Lemos SM. Tools for evaluation of restriction on auditory participation: systematic review of the literature. Codas 2015;27:400-6.

19. Bae S, Lee S, Lee S, et al. Combined effect of self-reported hearing problems and level of social activities on the risk of disability in Japanese older adults: A population-based longitudinal study. Maturitas 2018;115:51-5.

20. Lichtenstein MJ, Bess FH, Logan SA. Diagnostic performance of the hearing handicap inventory for the elderly (screening version) against differing definitions of hearing loss. Ear Hear 1988;9:208-11.

21. Tomioka K, Ikeda H, Hanaie $\mathrm{K}$, et al. The Hearing Handicap Inventory for Elderly-Screening (HHIE-S) versus a single question: reliability, validity, and relations with quality of life measures in the elderly community, Japan. Qual Life Res 2013;22:1151-9.

22. Demographics of Russia. 2017 https://en.wikipedia.org/wiki/ Demographics_of_Russia (Accessed 5 Nov 2017).
23. WHO. Deafness and hearing loss. Fact sheet. 2018 http://www.who. int/mediacentre/factsheets/fs300/en/ (Accessed 18 Mar 2018).

24. Ikeda N, Murray CJ, Salomon JA. Tracking population health based on self-reported impairments: Trends in the prevalence of hearing loss in US adults, 1976-2006. Am J Epidemiol 2009;170:80-7.

25. Helzner EP, Cauley JA, Pratt SR, et al. Race and sex differences in age-related hearing loss: the Health, Aging and Body Composition Study. J Am Geriatr Soc 2005;53:2119-27.

26. Hannula S, Bloigu R, Majamaa K, et al. Self-reported hearing problems among older adults: prevalence and comparison to measured hearing impairment. J Am Acad Audiol 2011;22:550-9.

27. Hoffman HJ, Dobie RA, Losonczy KG, et al. Declining prevalence of hearing loss in us adults aged 20 to 69 years. JAMA Otolaryngol Head Neck Surg 2017;143:274-85.

28. Ciletti L, Flamme GA. Prevalence of hearing impairment by gender and audiometric configuration: results from the National Health and Nutrition Examination Survey (1999-2004) and the Keokuk County Rural Health Study (1994-1998). J Am Acad Audiol 2008;19:672-85

29. Agrawal Y, Platz EA, Niparko JK. Prevalence of hearing loss and differences by demographic characteristics among US adults: data from the National Health and Nutrition Examination Survey, 19992004. Arch Intern Med 2008;168:1522-30.

30. Cruickshanks KJ, Dhar S, Dinces E, et al. Hearing impairment prevalence and associated risk factors in the Hispanic Community Health Study/Study of Latinos. JAMA Otolaryngol Head Neck Surg 2015;141:641-8.

31. Agrawal Y, Platz EA, Niparko JK. Risk factors for hearing loss in US adults: data from the National Health and Nutrition Examination Survey, 1999 to 2002. Otol Neurotol 2009;30:139-45.

32. Shargorodsky J, Curhan SG, Curhan GC, et al. Change in prevalence of hearing loss in US adolescents. JAMA 2010;304:772-8.

33. Lin FR, Thorpe R, Gordon-Salant S, et al. Hearing loss prevalence and risk factors among older adults in the United States. $J$ Gerontol A Biol Sci Med Sci 2011;66:582-90.

34. Lin FR, Niparko JK, Ferrucci L. Hearing loss prevalence in the United States. Arch Intern Med 2011;171:1851-2.

35. Bainbridge KE, Hoffman HJ, Cowie CC. Risk factors for hearing impairment among U.S. adults with diabetes: National Health and Nutrition Examination Survey 1999-2004. Diabetes Care $2011 ; 34: 1540-5$

36. Lin FR, Maas P, Chien W, et al. Association of skin color, race/ ethnicity, and hearing loss among adults in the USA. J Assoc Res Otolaryngol 2012;13:109-17.

37. Lalwani AK, Katz K, Liu YH, et al. Obesity is associated with sensorineural hearing loss in adolescents. Laryngoscope 2013;123:3178-84.

38. Li CM, Zhang X, Hoffman HJ, et al. Hearing impairment associated with depression in US adults, National Health and Nutrition Examination Survey 2005-2010. JAMA Otolaryngol Head Neck Surg 2014;140:293-302

39. Gispen FE, Chen DS, Genther DJ, et al. Association between hearing impairment and lower levels of physical activity in older adults. J Am Geriatr Soc 2014;62:1427-33.

40. Jun HJ, Hwang SY, Lee $\mathrm{SH}$, et al. The prevalence of hearing loss in South Korea: data from a population-based study. Laryngoscope 2015;125:690-4.

41. Lohi V, Hannula S, Ohtonen P, et al. Hearing impairment among adults: the impact of cardiovascular diseases and cardiovascular risk factors. Int J Audiol 2015;54:265-73.

42. Hong JW, Jeon JH, Ku CR, et al. The prevalence and factors associated with hearing impairment in the Korean adults: the 2010-2012 Korea National Health and Nutrition Examination Survey (observational study). Medicine 2015;94:e611.

43. Chang J, Ryou N, Jun HJ, et al. Effect of cigarette smoking and passive smoking on hearing impairment: data from a populationbased study. PLoS One 2016;11:e0146608.

44. Park YH, Shin SH, Byun SW, et al. Age- and gender-related mean hearing threshold in a highly-screened population: the Korean National Health and Nutrition Examination Survey 2010-2012. PLoS One 2016;11:e0150783.

45. Bainbridge KE, Hoffman HJ, Cowie CC. Diabetes and hearing impairment in the United States: audiometric evidence from the National Health and Nutrition Examination Survey, 1999 to 2004. Ann Intern Med 2008;149:1-10.

46. Newman CW, Weinstein BE, Jacobson GP, et al. Test-retest reliability of the hearing handicap inventory for adults. Ear Hear 1991;12:355-7.

47. Newman CW, Jacobson GP, Hug GA, et al. Practical method for quantifying hearing aid benefit in older adults. J Am Acad Audiol 1991;2:70-5. 